\title{
INDIVIDUALISMO Y ECONOMICISMO COMO PARADIGMAS DE LA MODERNIDAD (A propósito de Postmodernidad: decadencia o resistencia, de $\mathrm{J}$. Ballesteros)
}

\begin{abstract}
- as nociones de modernidad, modernización y postmodernidad están en el centro de un debate que no puede calificarse como reciente, pero que aún conserva ${ }^{1}$ buena parte de los ingredientes que concitaron el interés de no pocos destacados representantes de la intelligentsia occidental. El último libro del profesor Ballesteros $^{2}$, junto con los trabajos de B. Santos ${ }^{3}$, constituyen la más reciente intervención en esa polémica, aunque, como trataré de hacer ver, las suyas no son una reflexión ceñida a los términos habituales de la discusión por dos razones: en primer lugar, por la singularidad de la propia noción de postmodernidad que proponen (y especialmente la de Ballesteros, aunque se trata de posiciones, insisto, ampliamente coincidentes) y además, y esto es posiblemente lo más interesante, por cuanto en el curso de esos ensayos se abordan cuestiones que sin exageración cabe considerar como centrales para la filosofía jurídica y política en la actualidad. En lo que sigue, me atendré casi exclusivamente al trabajo del profesor Ballesteros, cuyas páginas podrían quizás ser calificadas como «reflexiones intempestivas», de acuerdo con el sentido que para Nietzsche -un filósofo al que el autor ha dedicado algunos trabajos anteriores desde una profunda y discrepante atención- tiene la expresión, pero en ningún caso suponen un alejamiento de los problemas clásicos de este sector del pensamiento.

El núcleo de la tesis que formula Ballesteros es, en mi opinión, la necesidad de profundizar en la crítica del lastre fundamental de la modernidad, al que se une también el de la herencia
\end{abstract}

${ }^{1}$ Aunque, obviamente, no puede recogerse aquí toda la bibliografía existente, baste recordar, entre otros, Lyotard 1984, Habermas 1985 y 1989, Foster 1988, Pico 1988.

${ }^{2}$ Ballesteros, 1989.

${ }^{3}$ Me refiero a la línea de investigación que viene desarrollando Boaventura Santos desde 1977, y de la que me limitaré a destacar Santos 1987, 1988, 1989. 
que nos lega la Ilustración. En otras palabras: frente a quienes reivindican que las razones de las crisis que caracterizan nuestro momento histórico deben encontrarse en el abandono o en la inconsecuencia en que se ha dejado caer el proyecto de la modernidad ${ }^{4}$, trata de poner de relieve las deficiencias básicas de dicho proyecto, en el orden epistemológico, antropológico, ético, jurídico, político y económico. Sin embargo, lo que singulariza su análisis es precisamente el hecho de que tales críticas no suponen una convergencia con las propuestas de los representantes de lo que se viene llamando postmodernidad. Muy al contrario, no sólo el diagnóstico sino también la terapia, si es que puede hablarse así, son radicalmente diversos.

Aun cuando discrepo de la conveniencia de reivindicar el término «postmodernidad» como superación del proyecto de la Ilustración, me parece difícilmente reprochable la versión que ofrece Ballesteros de las nociones centrales de la discusión: modernidad, modernismo, modernización, postmodernidad, postmodernismo e incluso tardomodernidad, tal y como aparecen descritos ya en el prólogo y posteriormente analizados, sobre todo en los capítulos 7 y 8: me refiero al cuidado con el que se ha rastreado el origen histórico de esos conceptos, lo que aparece, como en él es habitual, rigurosamente documentado. El problema es que, precisamente en la medida en que una de las características de este ensayo es que no está dominado por el complejo de quedar en minoría descrito por Ionescu en $E l$ rinoceronte (complejo al que el propio Ballesteros se refiere como una de las deficiencias de nuestra condición actual), su propuesta, ya desde el punto de partida puramente semántico, corre el riesgo de incomprensión, o, al menos, el de sumar dos dificultades añadidas: la de tener que explicar, en primer lugar, que el uso habitual de los términos postmodernidad y tardomodernidad (con la excepción de sus ya mencionadas coincidencias básicas con B. Santos) no es el que él mismo preconiza y por ello, en segundo lugar, la de tratar de replantear la discusión o, si se quiere decir así, de reconvertirla. Como decía, encuentro cierta dificultad en hacer comprensible, hoy, que, en realidad, lo mejor del proyecto ilustrado se encuentra en la postmodernidad, mientras que los efectos perversos de la modernidad serían sin embargo los que habrían acabado por imponerse como significativos de la modernidad (como ingredientes de la modernización), que esgrimiría como postmodernidad lo que no es sino

${ }^{4}$ En ese sentido, por todos, Habermas 1989. 
decadente tardomodernidad (de Derrida ${ }^{5}$ al Pensiero debole).

Pero, ¿cuáles son sus reticencias frente a la modernidad? Según creo, puede reconducirse esencialmente a estas dos: individualismo y economicismo. En el núcleo, sin embargo, se encuentra la crítica a la categoría de emancipación, el auténtico emblema de la Ilustración, en la lectura que, por ejemplo, Habermas hace de la misma, por encima del lema kantiano de la autonomía, del que deriva. Es precisamente la noción individualista de emancipación la que subvertiría buena parte de lo que Ballesteros acepta, incluso como fundamento de su propia posición, de las tesis de Kant. Ella estaría en la raíz, desde luego, del carácter relativista y etnocéntrico que denuncia como características del mundo moderno. Por otra parte, el economicismo, que encaja perfectamente con la ideología liberal-individualista, está en el origen de la autonomización primero y de la hegemonía después, de la ratio oeconomica en el orden social (ético y político): creo que compensa detenerse en estos dos extremos.

En primer lugar, pues, la conciencia de separación, de especificidad (que, según encontramos en el orden jurídico -Domat, Kant- se basa en el carácter «auténticamente natural» de las instituciones, ergo de las normas que regulan el orden privado, que es fundamentalmente el orden mercantil y civil), separación que en la sociedad industrial se acentúa hasta la esquizofrenia como mostrara un lúcido ensayo de Bell ${ }^{6}$, hace ya más de diez años, aunque sea preciso reconocer, con Ballesteros, la tendencia actual a una nueva uniformidad, o, para decirlo con él, a una hegemonía del orden económico, de su razón, de sus criterios y objetivos también en el ámbito cultural, y no sólo en el político o en el estrictamente social. En segundo lugar, el carácter puramente técnico (esto es, una vez abandonado el recurso de legitimidad del iusnaturalismo, se arguye la perfecta neutralidad y positividad) del mundo económico, que converge con el paradigma de progreso y de cientificidad a los que, por cierto, Ballesteros dedicó buena parte de un libro anterior ${ }^{7}$ y que sitúa la

5 A quien Ballesteros no duda en calificar como el exponente de la filosofía postestructuralista, más que de la posmodernidad. Cfr. Derrida, 1984. Sobre la posición que representa Derrida y las críticas formuladas a ella, vid. la respuesta que ofrece Barberá en esta misma sección de la revista.

${ }^{6}$ Bell 1977. No hay que olvidar que Bell adelantó la noción de sociedad posindustrial y su análisis: Bell 1976.

${ }^{7}$ Ballesteros 1986. Una vez más pueden encontrarse amplias coincidencias entre el análisis de Ballesteros sobre los supuestos, tesis y crítica del paradigma de las ciencias modernas y el que viene realizando B. Santos a través de sus 
esfera económica como el detentador casi exclusivo de la cientificidad y la racionalidad, tal y como escribía hace poco J. A. Valente ${ }^{8}$, y más concretamente su hipótesis metodológica central, de carácter no sólo individualista: el homo oeconomicus como individuo egoísta racional, que como tal principio metodológico pretende ser más que el modelo ideológico del individualismo posesivo ${ }^{9}$ (habría que matizar aquí, en mi opinión, la crítica al análisis económico del Derecho y de la política: reconocer que es un instrumento de trabajo, una hipótesis que, como tal, puede ser útil para explicar procesos, instituciones, conductas y normas concretas, lo que es muy distinto de proponer el «marketing» como sustitutivo del discurso práctico, de la complejidad del orden ético, social y político). Es a éste a quien atribuye Ballesteros el legado más criticable: el espíritu cuantitativo, lo que Marcel y Fromm llamaron la «primacía del tener», que conllevan la reducción de la economía a crematística, el imperio de la moral del éxito, la reducción del hombre a objeto y la consiguiente aparición de los fenómenos de explotación y marginación que inevitablemente comporta el capitalismo, que, sin exageración, concita el grueso de sus críticas, y no es la menor el hecho de que resulte inconciliable con la democracia, lo que por cierto, debería ser matizado: puede compartirse la tesis de que la «profundización de la democracia» exige una superación del modelo capitalista, como lo dice Ballesteros, apoyándose explícitamente en las tesis de E. Díaz, pero ello no justifica, en mi opinión, la total descalificación del análisis de Schumpeter, la negación de que la democracia surge, mal que pese, en ese contexto económico, la necesidad de no satanizar el capitalismo, pues lo contrario implicaría necesariamente su simplificación.

trabajos sobre epistemología (especialmente en el ámbito de las ciencias sociales): Santos caracteriza nuestro momento como una fase de transición entre dos paradigmas, el segundo de los cuales supondría encontrar un nuevo sentido común («con más sentido aunque sea menos común»), esfuerzo en el que se destaca el papel central de la reflexión hermenéutica, del círculo hermenéutico, para superar un paradigma caracterizado por un pensamiento basado en las dicotomías (sujeto/objeto, naturaleza/sociedad, Estado/sociedad civil), y llegar a comprender la ciencia como «práctica social de conocimiento».

${ }^{8}$ Valente 1989.

${ }^{9}$ Sobre la trascendencia de la hipótesis del individualismo metodológico (propia de una orientación dominante en el análisis económico) en el ámbito de ciencias sociales, y específicamente en los órdenes ético, jurídico y político, vid. entre los trabajos de Calsamiglia 1987, Garzón Valdés 1987, Pellicani 1989 y la discusión a partir de las tesis de Laporta en la sección sobre representación y democracia, en Doxa, 6 (1989), especialmente las posiciones al respecto de Garzón Valdés (con un comentario crítico de De Lucas). 
En efecto, lo que aquí se denuncia son los riesgos - ¿inevitables?- del proceso de racionalización magistralmente examinado por Weber, también con su característica de «jaula de hierro». Precisamente por revisar el carácter etnocéntrico de ese proyecto, resultan más evidentes aún las limitaciones, desde la dimensión de globalidad o universalidad, limitaciones que, según se ha reiterado, afectan asimismo a buena parte de quienes critican los supuestos en cuestión, y en primer lugar a Marx. Se trata, desde luego, del ámbito ecológico, del problema de la paz y la existencia de los bloques, y de la solidaridad ante el crecimiento de problemas de paro y de marginación progresiva de amplios sectores de población en los países desarrollados, junto a la necesidad de un nuevo orden económico internacional para corregir los desequilibrios que comporta la situación de un Tercer Mundo que, además, ya no se contenta con estar «a las puertas», sino que comienza a acuciar a las sociedades «del norte», por ejemplo, con los movimientos de emigración que van a modificar considerablemente las estructuras demográficas de esos países y ante los cuales comienza a perfilarse un intento de crear lo que algunos han llamado ya una «nueva frontera de la Comunidad Europea», sobre todo frente a emigrantes norteafricanos y sudamericanos, para los que Europa, concretamente, venía siendo no sólo un espacio de asilo y acogida, sino una esperanza de trabajo y mejora de vida. En esos problemas, que Ballesteros califica como las cuestiones centrales del «habitar humano», el reto que plantea la postmodernidad como resistencia (capítulo 8 y toda la cuarta parte del libro, donde se recogen sus propuestas) es donde cabe advertir quizás una toma de posición excesiva y paradójicamente, o quizás no tanto, por lo que se verá, optimista, que, entre otras cosas, arranca de una valoración que me parece unilateralmente positiva de la potencialidad de transformación que se otorga a los sistemas de valores y a las aportaciones culturales de los que se hace depositario al Tercer Mundo. No creo que se trate del complejo de culpa colonialista/imperialista ahora tan fustigado a propósito del «caso Rushdie» que serviría para poner de manifiesto una vez más la superioridad de una concepción del mundo propia de la tradición occidental frente a meaculpismos más o menos vergonzantes. La argumentación, tal y como se recoge, por ejemplo, en la página 126, está matizada por la necesidad de evitar el «antioccidentalismo», pero desde la afirmación de que es entre las víctimas del ayer de donde inevitablemente cabe esperar la posibilidad de regeneración, una confianza que no puede dejar de evocar los versos de Blake -la salvación está ante la puerta precisamente en el momento 
de desolación- y que, más que las tesis de Toynbee sobre la ambigüedad de nuestra condición histórica (pág. 101) serían, en mi opinión, la mejor expresión del sentido del ensayo, que no puede desligarse de la concepción trascendente que sostiene su autor. La misma sobredosis de optimismo -si se permite la expresión- se encuentra tras el análisis de lo que Ballesteros, apoyándose en J. B. Elsthain, y en A. Bocchetti, denomina «neofeminismo». No es que resulte más o menos difícil o utópico esa convergencia de «animus» y «anima» de la que nos habla el autor. En mi opinión, para que se produzca tal convergencia es preciso, en primer lugar, culminar los objetivos de lo que él denomina el «primer feminismo» (y me refiero a lo que quizá habría que considerar entonces como paleofeminismo, esto es, a la reivindicación del reconocimiento jurídico pleno, como sujeto de derechos, como personas, no ya a lo que casi todos denominamos «feminismo»e identificamos con las tesis de S. de Beauvoir), el reconocimiento efectivo de la igualdad de derechos y oportunidades, por ejemplo, de un modo especialísimo en lo que se refiere al mercado de trabajo. Por otra parte, sería necesario quizás un análisis más detallado de las repercusiones sobre el modelo familiar, sobre las estructuras de pareja, de las modernas «técnicas de reproducción asistida» que, por otra parte, como es sabido, han constituido y aún constituyen hoy quizás el problema que divide más radicalmente el pensamiento feminista. Por lo demás, la convergencia en cuestión, más que significativa de un neofeminismo, sería en todo caso expresión de un modelo de humanismo -no veo forma de eludir el término- en coherencia con los postulados de ecumenismo/recuperación de la naturaleza/solidaridad, cuyo modelo es el de Gandhi. Dicho de otro modo, no es por una nueva forma de feminismo por lo que apuesta el autor, y por esa razón no considero del todo adecuado que se utilice esa referencia, aunque esté justificada en parte como uno de los síntomas de la crisis de la modernidad y de los retos consecuentes.

En último lugar quisiera referirme al tratamiento de los derechos humanos. En el ensayo se recoge un análisis crítico, a mi juicio de enorme actualidad ${ }^{10}$, sobre el lastre ideológico de la

${ }^{10}$ Nuevamente he de insistir en que esto supone una crítica anterior (la realizada en Ballesteros 1987) al paradigma del positivismo jurídico (en especial del formalismo legalista), a sus conceptos básicos (por ejemplo, la identificación entre Derecho y ley, el monopolio estatal del Derecho, la separación entre Derecho y Moral). Sobre la dimensión jurídico-política ha profundizado B. Santos, desarrollando las tesis del pluralismo jurídico (así, los cuatro ámbitos 
fundamentación de los derechos humanos como derechos subjetivos, que se apoyaría en el individualismo (por tanto en el voluntarismo) y en la concepción patrimonialista, especialmente en el primero, por lo que se refiere a la versión más reciente, y que podríamos identificar en las posiciones de Muguerza y Savater ${ }^{11}$. A partir de un concepto de derechos largamente vinculado con la noción de necesidades que justificarían la presentación de los mismos como claims en el sentido fuerte del término ${ }^{12}$ (así, por ejemplo, páginas 59 a 64, 78, 98, 146 y siguientes) se mantiene la característica de inalienabilidad como el rasgo básico de identificación de los derechos humanos. El problema, en mi opinión, es que, aunque como ha señalado Laporta ${ }^{13}$, de acuerdo con Meyers y McConnell ${ }^{14}$, resulta necesario distinguir la nota de inalienabilidad de los derechos y el carácter absoluto de los mismos, lo cierto es, en primer término, que no se puede defender el carácter absoluto de los derechos, ni siquiera del que Ballesteros entiende como fundamental, el derecho a la vida, y, en segundo lugar, que si se entiende inalienabilidad no sólo como negación de la capacidad de venta (de enajenación) de los derechos, sino como negación también de la capacidad de disposición de los mismos, como irrenunciabilidad, o, como dice Laporta, «inmunidad respecto al propio status moral... el propio titular está obligado a respetar sus propios derechos o está inmunizado normativamente frente a sí mismo», coincidiendo con la argumentación del autor de libro a lo largo de ese último capítulo, si, como decía, se entienden así los derechos, no sería posible establecer una preferencia entre los mismos que implicase, en casos concretos, la renuncia. Esa es la razón, por ejemplo, de que a lo largo del libro se critique ampliamente supuestos como el suicidio o el aborto, sin advertir que, en ese caso, tampoco podría admitirse la libre disposición de la vida (su puesta en riesgo) por mor de la defensa de la fe, la patria u otros bienes (y derechos) propios o ajenos, lo que, a mi juicio, es, por el contrario, perfectamente defendible. Junto a ello, es evidente que el fundamento de los derechos no puede desligarse, en la concepción del autor,

que le permiten hablar de interlegalidad o la crítica a la justicia «formal», coincidente en gran medida con el análisis que ofrecen, por ejemplo, Arnaud y Ferrari) y ofreciendo otra dimensión de los derechos humanos, desde la noción de reciprocidad, como praxis social emancipatoria).

${ }^{11}$ Muguerza 1988, Savater 1989.

${ }^{12}$ Desde luego, inspirado en MacCormick 1977.

${ }^{13}$ Laporta 1988.

${ }^{14}$ Meyers 1985, McConnell 1984. Sobre la confusión también Feinberg 1980. 
de la visión trascendente, más concretamente, cristiana: si ello constituye un obstáculo para proporcionar un concepto y fundamentación de pretensiones universales es una cuestión a la que, coherentemente, intenta proporcionar una respuesta negativa. No cabe duda que en este, como en otros aspectos, se discrepará de los análisis y tomas de posición contenidas en el libro, pero lo que también hay que reconocer es que éste constituye un esfuerzo doblemente valioso por cuanto además de analizar una vez más las características de la crisis, no se rehuye formular el propio modelo, aunque éste lleve aparejado, hoy, la condición de minoría que, no olvidemos, suele ir de la mano con la de resistente.

\section{BIBLIOGRAFÍA}

Ballesteros, Sobre el sentido del Derecho, Madrid, Tecnos, 1986.

- Posmodernidad: decadencia o resistencia, Madrid, Tecnos, 1989.

Ballesteros/De Lucas, «Sobre los límites del principio de disidencia», en el col. ed. por Peces-Barba, 1989.

Bell, El advenimiento de la sociedad postindustrial, Alianza, Madrid, 1976.

$\longrightarrow$, Las contradicciones culturales del capitalismo, Alianza, Madrid, 1977.

Calsamiglia, «Eficacia y Derecho», Doxa, 4, 1987.

Derrida, De la Gramatología, Siglo XXI, México, 1984.

Elsthain, Public Man, Private Woman in Social and Political Thought, Princeton, P.U.P., 1981.

Feinberg, Justice and the bounds of Liberty, Princeton, P.U.P., 1980.

Foster (ed.), La posmodernidad, Kairós, Barcelona, 1985.

Habermas, «La modernidad: un proyecto inacabado», en La postmodernidad (ed. de Foster), Kairós, Barcelona, 1985.

—_El discurso filosófico de la modernidad, Madrid, Tauros, 1989.

Laporta, «Sobre el concepto de derechos humanos», Doxa, 4, 1988.

Lyotard, La condición posmoderna, Cátedra, Madrid, 1984.

MacCormick, «Rights, Claims and Remedies», Law and Philosophy, 2, 1982.

Meyers, Inalienable Rights. A Defense, N. York, Columbia, U.P., 1985.

MacConnell, «The Nature and Basis of Inalienable Rights», Law and Philosophy, 3, 1984. 
Muguerza, «La disidencia como fundamento de los derechos humanos» (en el col. ed. por Peces-Barba, 1989).

Peces-Barba (ed.), El fundamento de los derechos humanos, Madrid, Debate, 1989.

Picó (ed.), Modernidad y Postmodernidad, Madrid, Alianza, 1988.

Santos, «The posmodern transition: Law and Politics», Amherst College, 1987 (trad. cast. de M. J. Añón incluida en este número de Doxa).

—-, Um Discurso sobre as Ciências, Porto, Afrontamento, $1988\left(2 .^{a}\right)$.

—_, Introduçao a uma Ciência pós-moderna, Porto, Afrontamento, 1989.

Savater, Ética del amor propio, Madrid, Mondadori, 1989.

Valente, «Crítica de la razón económica», El País, 28-II-1989. 